\title{
The effect of computer response time on user performance and satisfaction: A preliminary investigation
}

\author{
GARY L. DANNENBRING \\ St. Francis Xavier University, Antigonish, Nova Scotia B2G 1C0, Canada
}

\begin{abstract}
The present study was designed to investigate the effect of delays in the response of the computer on the performance of the user and his satisfaction with the system. While it is generally assumed that computer responses should be no longer than several seconds, the present study showed no effect of 5- or 10-sec fixed or variable delays on subjects debugging a simple BASIC program. These results have important implications for the design of large, multiuser timesharing systems.
\end{abstract}

It is a commonly held belief among computer scientists that computer response times of greater than several seconds result in decreased user performance. However, this opinion does not seem to be based on any empirical evidence. For example, Martin (1973) devotes an entire chapter to the response time requirements of interactive systems. Basically, he argues that response times of greater than $4 \mathrm{sec}$ are generally too long, and for some situations, response times need to be less than $2 \mathrm{sec}$. To provide psychological support for his arguments, Martin cites Miller (1968). However, Miller does not provide empirical evidence to support his points. He refers to the general properties of short-term memory and the psychological implications of interrupting an uncompleted task in arguing that response times should typically be 2 sec or less. Carbonell, Elkind, and Nickerson (1968) argue that response times must be short enough to be similar to the delays that normally occur in human conversation and that unpredictable response times are especially bad. Again, however, no evidence is provided that slow or variable response times actually result in decreased user performance. The importance of consistency of response time has also been stressed by Doherty, Thompson, and Boies (1972), Nickerson (1969), and Wood (1972). In all cases, the authors express their opinions of user performance and/or satisfactions which they base, apparently, on subjective impressions gained from observing users, rather than on evidence collected under controlled experimental conditions.

This research was supported by grants from the Natural Science and Engineering Research Council of Canada and the St. Francis Xavier University Council for Research. I would like to thank the Psychology Department and Lloyd Avant at Iowa State University for the use of the computer facilities during a sabbatical year, and also Kevin Briand, Steve Garnjobst, and Nancy LaRose for their assistance in data collection. Reprint requests may be sent to Gary Dannenbring, Department of Psychology, St. Francis Xavier University, Antigonish, Nova Scotia B2G IC0, Canada.
Recently, the importance of conducting better research on the psychological aspects of computing has been stressed. Moran (1981) states that "computer science, of course, has not been totally oblivious of the computer user ... . The treatment of user behavior, however, is typically cavalier" (p. 2). He argues that this is due to the dominance of computer science by the "attitudes of the technologist and the designer" (Moran, 1981, p. 2), when what is needed is a greatly increased input from psychologists. Brooks (1980) and Sheil (1981) evaluated the existing literature on the psychology of programming, an area in which a number of experimental studies have been conducted. They concluded that a good deal of research remains to be conducted and that improvements need to be made in the design and methodology of these studies.

The present study, then, is intended to be a preliminary experimental investigation into the effect of the response time of the computer on the performance of both beginning and experienced programmers, and their satisfaction with the system. Delays in response time were either fixed or variable, to test the opinion that variable response times create greater difficulties for users, which has been expressed in several papers (Carbonell et al., 1968; Doherty et al., 1972; Nickerson, 1969; Wood, 1972). The task required subjects to debug a simple BASIC program, a typical task faced by programmers. It is important to realize, however, that the implications of the results are necessarily limited and may not apply to other tasks performed by computer users (for more complete discussions of appropriate methodological considerations, see Brooks, 1980; Sheil, 1981).

\section{METHOD}

Subjects

Subjects were 100 students and faculty at St. Francis Xavier University, Iowa State University, and Ames (lowa) High School. Subjects from St. Francis Xavier University were volunteers; 
those from Iowa State received either $\$ 3$ or course credit for participating. All high school students were paid $\$ 3$.

There were two groups of subjects, each consisting of 50 subjects: (1) novice programmers, defined as those who had completed, or had almost completed, their first course in BASIC and had no other programming experience, and (2) experienced programmers, who had at least 1 year of programming experience and knowledge of at least one language other than BASIC.

\section{Apparatus and Design}

The subjects at St. Francis Xavier University were run on a PDP-11/34 computer; those at Iowa State used a PDP-11/04. The subjects were required to debug a simple BASIC program (see the appendix) in which there were seven errors, both syntactic and nonsyntactic. BASIC was run under an RT-11, Version 3, and was modified with a subroutine that detected carriage returns from the console and introduced the appropriate timed delay before the computer was ready for another line of input. In addition, the subroutine recorded the total number of carriage returns typed by the subject. There were five different computer response time conditions for both types of subjects, resulting in a total of 10 groups of subjects. The five conditions were (1) instant response time, (2) 5-sec fixed delay, (3) 10-sec fixed delay, (4) 5-sec variable delay, ranging from 1 to $9 \mathrm{sec}$, and (5) $10-\mathrm{sec}$ variable delay, ranging from 6 to $14 \mathrm{sec}$.

\section{Procedure}

The subjects were told that the experiment involved simulating conditions that might occur with a multiuser system and that we were interested in the effect of the computer's performance on the performance of the computer user. The nature of the program that they were to debug was described. They were asked to debug the program by retyping the entire line that contained the error rather than using the editing features of BASIC. This was done because subjects had learned BASIC on a variety of machines, and there was no way to insure that they knew the proper way to edit with RT-11 BASIC.

Once the subject understood the nature of the task, he was given a copy of the erroneous program to study for $5 \mathrm{~min}$ and was allowed to mark any corrections that were immediately obvious. After this, the subject was seated at the computer console and told that timing would begin as soon as the program was listed. Subjects were told to work as fast and as accurately as possible, since both time to completion and errors were being measured. The subject's task was completed when he was able to produce a correct run of the program (the subject also had a copy of the correct output). If the subject was unable to complete the task within a $30-\mathrm{min}$ time period, the session was terminated.

Upon completion of the debugging task, subjects were given a brief questionnaire. This asked them how many years of programming experinece they had and what languages they knew (to separate beginning programmers from experienced programmers), how easy they found the task, and how satisfied they were with the performance of the computer.

\section{RESULTS}

There were seven dependent variables measured in the present experiment. The first was the rated difficulty of the task, indicated by the subject on the questionnaire, where 1 was "very easy" and 7 was "very difficult." The second measure was the subject's satisfaction with the performance of the computer, with $1=$ "very satisfied" and $7=$ "very dissatisfied." Third, the total time (in seconds) to complete the task was measured. Since the artificial delays may have resulted in unnecessarily long completion times, the times recorded are the total times minus the response time delays. It should be realized, however, that subjects were often working during these delay times. The fourth dependent variable was the total number of "CNTR U"s (which deleted the current line) and "deletes" typed by the subject, indicating errors he made but corrected before the line was entered. Fifth, the total number of attempted runs (before the correct run) was recorded, which is a measure of the general skill and efficiency of the programmer. Similarly, we also recorded the number of times the subject requested a listing of the program (the sixth dependent variable). Finally, the total number of errors made by the subject, both syntactic and semantic, that were not corrected before the line was entered, was recorded.

An analysis of variance was run for each dependent variable, looking at the effects of the five delay conditions and two types of programmers. These analyses revealed, in general, highly significant differences between beginning and experienced programmers. First, there was an effect of type of programmer on the rated difficulty of the task $[F(1,90)=38.92, p<.0001]$, with beginners rating the task as more difficult. Beginning and experienced programmers differed in the time taken to complete the task $[F(1,90)=27.57, p<.0001]$, with experienced programmers requiring half the time taken by beginners. In actuality, a number of beginners failed to complete the task within the required $30 \mathrm{~min} ; 13$ of the 50 beginners were unable to complete the task, but all of the experienced programmers completed it. Thus, the mean completion time of $1,010 \mathrm{sec}(16.8 \mathrm{~min})$ for beginners actually underestimates the time the task would take. Beginning programmers also made more errors than experienced programmers, both errors they caught before entering the line (using CNTR U or delete) $[F(1,90)=8.15, p<.005]$ and other syntactic and semantic errors $[F(1,90)=10.03, p<.002]$. The final difference was in the number of program lists requested by the subject, with beginners requiring more listings $[F(1,90)=4.25, p<.04]$. The only factor on which beginning and experienced programmers did not differ was their satisfaction with the computer system $[F(1,90)$ $=2.73, \mathrm{p}>.1]$.

The response time of the computer had an effect only on the number of CNTR Us or deletes made by the subjects $[F(4,90)=3.01, p<.03]$, with fewer characters or lines deleted as delay and variability increased. There were no significant interactions between delay condition and programmer type for any of the dependent variables.

Finally, to investigate more closely the possible effect of variable computer responses a 2 by 2 by 2 analysis (5- or 10-sec delays, fixed or variable delays, and beginning or experienced programmers) was conducted 
for each dependent variable. These analyses revealed no significant main effects for response variability or response time and no significant interactions between these variables.

\section{DISCUSSION}

Finding that experienced programmers perform better than beginners on the indexes used in the present study is not terribly surprising. More interesting is the failure to find general effects of computer response time, either in total time or in delay (fixed or variable). Such a result is contrary to the generally accepted view that response times should typically be $2 \mathrm{sec}$ or less (see Martin, 1973) and that variable response times are especially detrimental (Doherty et al., 1972; Nickerson, 1969; Wood, 1972). The consistent lack of an effect of response time on the measures used in the present study (except for the number of CNTR Us and deletes typed) and, indeed, the lack of any appropriate trends make it unlikely that the inability to find an effect of computer response time is due to the size of the sample.

As noted, the notion that computer responses should be less than $2 \mathrm{sec}$ apparently comes largely from opinion rather than empirical evidence. In fact, in at least one experimental study (Boehm, Seven, \& Watson, 1971), subjects engaging in a problem solving task performed best when a 5-min "lockout" occurred after they were given results from the computer, although they tended to "dislike" the system more under lockout conditions. It was hypothesized that the lockout period forced the subjects to think more about the problem, resulting in more efficient use of the computer. Similarly, it could be argued that subjects in the present study were more careful under longer delay conditions, as reflected by the number of CNTR Us or deletes typed.

It is reasonable to conclude, then, that the response delays that occurred in the present study were not excessive, and if anything, may have caused the users to be somewhat more careful in their work. Such a result has important implications for the design of timesharing systems, as it may be possible to put more users on a given system without affecting the quality of their work than has typically been assumed. Obviously, it is important to note that the present study is a very limited case. First, logic would suggest that at some point there would be an effect of response time on user performance and/or satisfaction. Further studies will be needed to determine that point. Also, it is difficult to extrapolate from the present study to other tasks (text editing, accessing data bases, etc.). It is also possible that 5- or $10-\mathrm{sec}$ computer delays are excessive if the subject is engaging in a much longer task. Clearly, further research is needed.

\section{REFERENCES}

Boehm, B. W., Seven, M. J., \& Watson, R. A. Interactive problem-solving: An experimental study of "lockout" effects. AFIPS Conference Proceedings, 1971, 38, 205-210.

Brooks, R. E. Studying programmer behavior experimentally: The problems of proper methodology. Communications of the $A C M, 1980,23,207-213$.

Carbonell, J. R., Elkind, J. I., \& Nickerson, R. S. On the psychological importance of time in a time sharing system. Human Factors, 1968, 10, 135-142.

Doherty, W. J., Thompson, C. H., \& Bores, S. J. An analysis of interactive system usage with respect of software, linguistic, and scheduling attributes. In Proceedings of the 1972 International Conference on Cybernetics and Society. New York: IEEE, 1972.

Martin, J. Design of man-computer dialogues. Englewood Cliffs, N.J: Prentice-Hall, 1973.

Miller, R. B. Response time in man-computer conversational transactions. AFIPS Conference Proceedings, 1968, 33(Pt. 1), 267-277.

Moran, T. P. An applied psychology of the user, Computing Surveys, 1981, 13, 1-11.

Nickerson, R. S. Man-computer interaction: A challenge for human factors research. Ergonomics, 1969, 12, 501-517.

Sheil, B. A. The psychological study of programming. Computing Surveys, 1981, 13, 101-120.

WooD, R. C. Inferences from the UCSB on-line system for man-system interface design. In Proceedings of the 1972 International Conference on Cybernetics and Society. New York: IEEE, 1972.

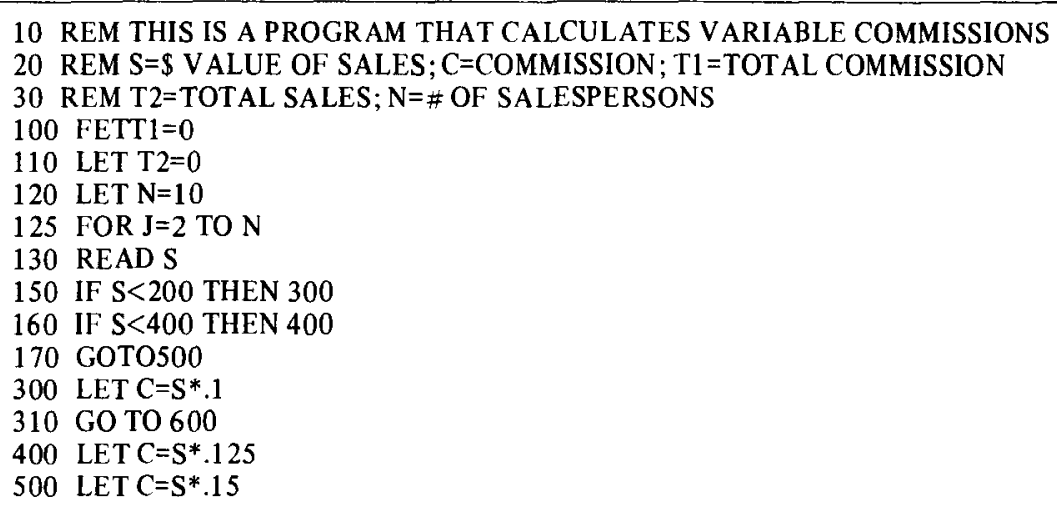




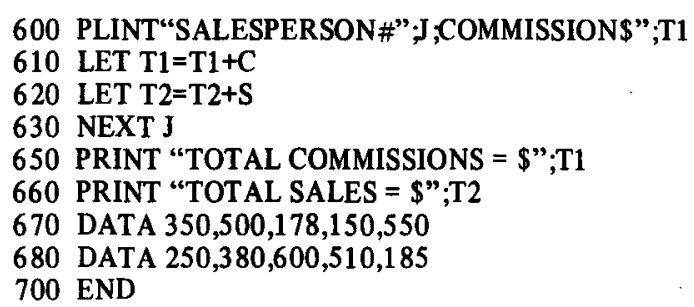

Correct Output

SALESPERSON\# 1 COMMISSION\$ 43.75 SALESPERSON\# 2 COMMISSION\$ 75 SALESPERSON\# 3 COMMISSION\$ 17.8 SALESPERSON\# 4 COMMISSION\$ 15 SALESPERSON\# 5 COMMISSION\$ 82.5 SALESPERSON\# 6 COMMISSION\$ 31.25 SALESPERSON\# 7 COMMISSION\$ 47.5 SALESPERSON\# 8 COMMISSION $\$ 90$ SALESPERSON\# 9 COMMISSION $\$ 76.5$ SALESPERSON\# 10 COMMISSION\$ 18.5 TOTAL COMMISSIONS $=\$ 497.8$ TOTAL SALES $=\$ 3653$

\begin{tabular}{lll}
\multicolumn{2}{c}{ Errors } & \\
\hline$\frac{1}{100}$ & Error & \multicolumn{1}{c}{ Correction } \\
\cline { 2 - 3 } 125 & FET & LET \\
170 & J=2 & J=1 \\
410 & GOTO (Last char zero) & GOTO \\
600 & (line missing) & GOTO 600 \\
600 & PLINT & PRINT \\
600 & COMMISSION \$" & "COMMISSION \$" \\
& T1 & C \\
& & \\
& & \\
\end{tabular}

